\title{
Correction to: Nutrition, Physical Activity, and Prescription of Supplements in Pre- and Post-bariatric Surgery Patients: a Practical Guideline
}

\author{
Mastaneh Rajabian Tabesh $^{1} \cdot$ Faezeh Maleklou $^{1} \cdot$ Fatemeh Ejtehadi $^{1} \cdot$ Zahra Alizadeh $^{1,2}$ (D) \\ Published online: 5 December 2019 \\ (C) Springer Science+Business Media, LLC, part of Springer Nature 2019
}

\section{Correction to: Obesity Surgery (2019) 29:3385-3400 https://doi.org/10.1007/s11695-019-04112-y}

In Table 7 the following corrections are required:

Vitamin B12 (cobalamin):

Post-surgery recommendation: $\mathrm{mg}$ must be changed to microgram (350-500 mg: 350-500 microgram/ 1000 mg monthly:1000 microgram monthly)

Folate (folic acid):

Post-surgery recommendation: mg must be changed to microgram (400-800 mg: 400-800 microgram/ 800-1000 mg: 800-1000 microgram)

The online version of the original article can be found at https://doi.org/ 10.1007/s11695-019-04112-y

Zahra Alizadeh

Z_alizadeh@tums.ac.ir

Mastaneh Rajabian Tabesh

mastaneh.tabesh@ut.ac.ir

Faezeh Maleklou

faezeh.maleklou88@gmail.com

Fatemeh Ejtehadi

ftmhejtehadi@gmail.com

1 Sports Medicine Research Center, Tehran University of Medical Sciences, Tehran, Iran

2 Department of Sports and Exercise Medicine, Tehran University of Medical Sciences, No. 7, Ale-ahmad Highway, Opposite of the Shariati Hospital, Tehran 14395-578, Iran
Post-surgery treatment: $1000 \mathrm{mg}$ of folate daily: 1000 microgram of folate daily)

Publisher's note Springer Nature remains neutral with regard to jurisdictional claims in published maps and institutional affiliations. 